Cinc rondalles mallorquines d'Antoni M. Alcover: català-txec. Traducció de Jaroslava Marešová i de Jana Vrátníková, versió catalana adaptació, introducció i edició a cura de M. Magdalena Gelabert i Miró. Escorcolls 5. Manacor: Institució Pública Antoni M. Alcover, 2OII, I5O p.

Cinc rondalles mallorquines d'Antoni M. Alcover: català-rus. Traducció d'Anna Urzhumtseva, versió catalana adaptació, introducció i edició a cura de M. Magdalena Gelabert i Miró. Escorcolls 6. Manacor: Institució Pública Antoni M. Alcover, 20II, I66 p.

Cinc rondalles mallorquines d'Antoni M. Alcover: català-romanès. Traducció d'Anca Bărbulescu, versió catalana adaptació, introducció i edició a cura de M. Magdalena Gelabert i Miró. Manacor. Escorcolls 7. Manacor: Institució Pública Antoni M. Alcover, 2OII, I56 p.

Cinc rondalles mallorquines d'Antoni M. Alcover: català-anglès. Traducció de Mònica Marcos-Llinàs, versió catalana adaptació, introducció i edició a cura de M. Magdalena Gelabert i Miró. Escorcolls 9. Manacor: Institució Pública Antoni M. Alcover, 2OI2, I56 p.

\title{
Cinc rondalles mallorquines d'Antoni M. Alcover
}

M. Magdalena GelaberT i Miró

Institució Pública Antoni M. Alcover, Manacor

Antoni M. Alcover i la transcendència de l'Aplec de Rondaies Mallorquines d'En Jordi des Racó

Antoni M. Alcover i Sureda (Manacor, 2 de febrer de I862 - Palma, 8 de gener de I932), un dels principals folkloristes de tots els temps dels Països Catalans, dedicà una part molt important de la seva vida a la recerca de materials etnogràfics diversos. Ha destacat, sobretot, per l'Aplec de Rondaies Mallorquines d'En Jordi des Racó, que començà a publicar l'any I896. Des d'aquesta data i fins a I930 s'anaren editant els diversos volums que el conformen i, alhora, s'anaren reeditant, a mesura que s'exhaurien, atès que des del primer moment tingueren un gran èxit de públic i una acceptació extraordinària entre els mallorquins.

Antoni M. Alcover morí dos anys després de publicar l'últim volum —el I932i posteriorment el seu deixeble Francesc de Borja Moll publicà l'aplec en uns volums de mida més reduïda i manejadissa. Convertí els deu volums que conformaven l'edició inicial en vint-i-quatre, que anaren sortint a partir de I936. ${ }^{\mathrm{I}}$ Podem afirmar que es tracta del principal best-seller de la literatura de les Illes Balears de tots els temps ja que se n'han editats milers i milers de volums i s'ha considerat el clàssic per excel-lència: el millor regal que se solia elegir per a la primera comunió dels infants, per a dates assenyalades o el present que es feia - i es fa encara- a cada un dels infants que participen en diversos actes populars o culturals.

I. Alcover, Antoni M. (I936-I972): Aplec de Rondaies Mallorquines d'En Jordi d'es Racó. Palma: Editorial Moll, 24 volums. 
Aquesta edició de l'editorial Moll es coneix com l'edició popular de les rondalles i és plenament vigent i estesa encara avui. Des de l'any 2006, l'edició popular conviu amb l'edició crítica — publicada també per l'editorial Moll—, a cura de Josep Antoni Grimalt i Jaume Guiscafrè, que tant va adreçada a un públic popular interessat en el tema com a lectors investigadors o especialistes. ${ }^{2}$ Es tracta d'una edició acuradíssima i completa que inclou el nombre corresponent als tipus dels catàlegs generals - l'índex Aarne-Thompson i l'ATU_, el text de la rondalla adscrita al tipus, una llista de les edicions i de les traduccions que s'han fet de la rondalla, la transcripció de les anotacions corresponents a la rondalla extretes de les sis llibretes manuscrites en què mossèn Alcover consignava el material que arreplegava de la tradició oral i que li servia de base per a l'elaboració posterior dels textos, la seqüència de motius presents a cada rondalla, notes crítiques comparatives i comentaris, etc. L'any 2013 s'ha publicat el sisè volum dels —aproximadament deu-que constituiran aquesta nova edició.

Resulta interessant la trajectòria històrica d'aquest aplec que s'ha difós al llarg de més de setanta anys a través dels llibres i per la publicació en revistes, de caràcter molt divers, de nombroses rondalles. Aquests llibres han estat -i són- comprats i llegits, sovint en veu alta, per la gent de totes les edats i condicions socials. Són una lectura popular consolidada i poques són les cases de Mallorca on no hi ha algun tom de les rondalles d'Alcover. Així, es compleix un dels objectius cabdals de l'autor: tornar-les al poble del qual havien sortit, renovades i restaurades, perquè poguessin retornar al canal de l'oralitat.

L'Aplec, però, no solament ha seguit el camí dels llibres, sinó que s'ha anat introduint en els diferents canals tecnològics a mesura que s'han anat popularitzant. Així, en un primer moment, a l'inici dels anys seixanta, i per iniciativa de Mn. Guillem Fiol i de Francesc de B. Moll, s'iniciaren els enregistraments i la difusió radiofònica posterior de les rondalles. ${ }^{3}$ El mateix Moll actuava d'adaptador i de narrador i, amb els mitjans precaris propis de l'època, s'emetien a través de Ràdio Popular, una emissora catòlica que tenia una gran acceptació per part del públic mallorquí. L'èxit que assoliren a Mallorca aquestes emissions va ser extraordinari i, encara avui, es recorden aquelles emissions com una fita dins les famílies de l'època.

De la mateixa manera, pels anys vuitanta la companyia Zanoguera-Alfaro, dirigida per Joan Mas, publicà en 24 cassets una important selecció de les rondalles d'Alcover. Amb el títol Ses Rondaies Mallorquines. Recull de Mossèn Alcover, aquesta companyia d'actors donà vida als personatges de les rondalles amb uns muntatges senzills però que resulten plenament atractius per al públic d'avui. ${ }^{4}$ Destaca, sobretot, la fidelitat al text d'Alcover i l'encertat acompanyament de música popular a càrrec del grup Música Nostra. Miquel Àngel Sancho i Joan Bibiloni les editaren a través de la productora Blau.

2. Alcover, Antoni M. (1996-): Aplec de Rondaies Mallorquines d'En Jordi d'es Racó. Edició a cura de Josep A. Grimalt amb la col-laboració de Jaume Guiscafrè. Palma: Editorial Moll, vol. I (1996), vol. II (I998), vol. III (200I), vol. IV (2006), vol. V (20I0), vol. VI (20I3).

3. Aplec de Rondaies Mallorquines d'En Jordi d'es Racó. Contades per Francesc de Borja Moll i el quadre escènic de Ràdio Popular. Gravacions radiofòniques originals de I959. Palma: Editorial Moll, 20Io, format CD.

4. Ses Rondaies Mallorquines. Recull de Mossèn Alcover. Companyia Zanoguera-Alfaro. Adaptació i direcció de Joan Mas. Palma: Edicions M. A. Sancho / Producció Blau, I986, format casset. 
D'aleshores ençà, hi ha hagut noves edicions de les rondalles en format de CDROM, com ara les d'A-Block — anteriorment Block Mèdia-, que incloïen la rondalla en dibuixos animats i una síntesi de la rondalla al costat de diverses propostes ludicoeducatives com embarbussaments, expressions lingüístiques, refranys, etc. ${ }^{5}$ Notables són les aportacions del músic Joan Bibiloni i el seu equip en les versions musicades d'un bon nombre de rondalles. ${ }^{6}$ Bibiloni també ha treballat en adaptacions de rondalles i en els dibuixos animats en un format senzill. També ha treballat en versions de rondalles musicades pel Col-lectiu d'Artistes Lírics i una de les darreres aportacions és la del músic Antoni Nicolau -membre del grup de música jove Ocults-, que publicà l'any 2013 el CD Venim de rondalles, amb una visió d'aquestes molt personal i innovadora. ${ }^{7}$

D'altra banda, la majoria de mestres de les Illes ha usat, en algun moment, les rondalles com a eina educativa i, a escala institucional, la conselleria d'Educació i Cultura del Govern de les Illes Balears, ajuntaments diversos de les Illes i el COFUC han editat materials didàctics i de suport a partir de les rondalles. La utilització de les rondalles com a eina didàctica les ha esteses significativament entre la comunitat educativa.

L'Aplec ha estat també font d'inspiració d'artistes plàstics que han recreat els personatges i l'entorn de les rondalles. Des de les primeres il-lustracions dels germans Josep i Francesc de Borja Moll, que són les que més identifiquen al primer cop d'ull les rondalles mallorquines, fins a les més actuals i innovadores hi ha un gran ventall d'estils i tècniques. Per exemple, els olis i les aquarel-les de les rondalles del pintor mallorquí Gabriel Pellicer, i d'altres pintors com Joan Guerra o Jaume Poma; les escultures de Pere Pujol o Pere Pasqual; les il-lustracions de Joan Brunet, d'Antoni Galmés, de Pere Pasqual, de Nívola Uyà, de Ramon Cavaller, de Sebastià Riera —especialista en manga-, Francesc Barceló, Pau Oliver GarcíaDelgado, Miquel Salvà, Pere Joan, Irene Bordoy, Aina Bonner, Llorenç Vidal, entre molts d'altres, són una mostra de com l'Aplec ha inspirat artistes molt diversos.

És especialment significativa l'aplicació de les rondalles al món del teatre. A Mallorca, cada any es representen rondalles tant per part de companyies professionals com de grups escolars, de persones grans o de membres d'associacions diverses. Ja es pot comptar per centenars el nombre de muntatges i representacions.

Davant aquests fets, podem considerar espectacular la transcendència de l'Aplec de Rondaies Mallorquines d'En Jordi des Racó en camps ben diferents.

\section{La Institució Pública Antoni M. Alcover de Manacor i les rondalles}

L'Ajuntament de Manacor - la ciutat que va veure néixer Antoni M. Alcovercreà una institució en honor de la seva figura. El 20 de setembre de l'any 1999 s'aprovaren els estatuts, l'article primer dels quals diu així: «L'Ajuntament de Manacor conscient de la grandesa d'Antoni Maria Alcover i Sureda i de la seva obra, acorda crear una Fundació Pública amb el seu nom, que sigui acte d'homenatge,

5. Io de Io. Palma: A-Block / Documenta Balear, 2006, format DVD-ROM.

6. BIbILONI, Joan (2007): 45 cançons de rondalles per a infants. Palma: Satie Produccions Audiovisuals, format CD.

7. Nicolau, Antoni (20I3): Venim de rondalles. Manacor: Estudis CanRecó / Institució Pública Antoni M. Alcover, format CD. 
mostra dels seus records, estímul d'estudi i ciència, manifestació d'afecte cap a la nostra terra i els nostres valors, i llavors d'un gran arbre de cultura i harmonia.»

Des d'aleshores ençà, la Institució Pública Antoni M. Alcover treballa, entre d'altres, amb els fins i objectius següents: promoure, organitzar, gestionar, patrocinar i celebrar tot tipus d'actes i activitats per a la difusió general de la figura d'Antoni M. Alcover i la seva obra i també el bon nom de l'Illa i de Manacor; promoure l'estudi, recerca, coneixença i lligams de la literatura infantil, especialment de les nostres rondalles; promoure l'estudi, recerca, coneixença i rehabilitació de la cultura popular de Mallorca; la conservació, reunió i aprofitament científic de tot el llegat d'Antoni M. Alcover; obrir una sala-museu, amb els objectes, quadres, fotografies, etc., procedents dels familiars de Mossèn Alcover, de la família Moll i altres; publicar obres de Mossèn Alcover; instituir premis literaris, de recerca, d'art o de mèrits personals, amb el nom de la Institució Pública, i promoure la coneixença i germanor amb altres pobles del món, especialment els que Alcover va visitar tantes vegades per motius de feina.

Des dels seus inicis, la Institució Pública Antoni M. Alcover treballa amb la difusió de les rondalles des de diferents perspectives i mitjans. Ha organitzat, de manera continuada, contades de rondalles en directe tant des de la perspectiva dels professionals - actors i companyies teatrals - com des de la de les persones no professionals - joves, pares i mares, padrins i padrines - un poc expressives, que tinguessin interès a fer de baula transmissora de la tradició oral de contar rondalles.

Una altra de les iniciatives relacionades amb la transmissió de les rondalles fou la creació d'un programa televisiu d'abast comarcal que, amb el títol de Personatges i rondalles, serví per presentar diferents personalitats de la zona procedents de camps molt diversos: metges, advocats, empresaris, esportistes, investigadors, actors i actrius, pintors, fusters, perruquers, etc., i, a la vegada, serví com a model per demostrar que qualsevol persona, sigui el que sigui o faci el que faci, pot continuar la tradició de transmetre les rondalles oralment. El programa es dividia en dues parts: la primera era un reportatge sobre el personatge convidat i la segona la conformava la rondalla que contava, contextualitzada i explicada per la directora de la Institució, que coordinava i preparava els continguts i la presentació del programa de cada setmana al llarg d'un parell d'anys.

La idea provenia de l'acte estrella de la Setmana de Mossèn Alcover, una setmana d'actes que la Institució dedica cada any, a principis de febrer, a commemorar el naixement d'Antoni M. Alcover: la Marató de rondalles. La Setmana de Mossèn Alcover es clou amb una marató de rondalles de la qual ja hem celebrat nou edicions. Es tracta d'una contada de rondalles que es fa, de manera ininterrompuda, des de les nou del matí fins a les nou del vespre. Les sessions del matí solen ser destinades al públic escolar, tot i que totes els sessions són obertes a tothom, i conten les rondalles actors professionals, i les sessions del capvespre les protagonitzen personalitats destacades de diferents col·lectius. Així, han participat com a contadors de rondalles metges com el Dr. Antoni Mesquida, la Dra. Catalina Vadell o el Dr. Bartomeu Beltrán; batles; representants del món eclesiàstic; esportistes de renom com Elena Gómez, Miquel Àngel Nadal i Rafel Nadal; pintors com Joan Riera Ferrari i Rafel Perelló; economistes com el director del Centre de Recerca Econòmica, Antoni Riera; pianistes com Andreu Riera; músics com Tomeu Penya, i poetes com Josep Lluís Aguiló, entre molts d'altres. La idea era la mateixa, 
demostrar que les rondalles són a l'abast de tothom i que qualsevol persona, de qualsevol condició, en pot contar, si vol.

L'experiència d'aquests anys ens ha ajudat a percebre i demostrar la vigència de les rondalles; no es tracta d'un material solament històric, sinó ben viu i a l'abast de tothom, hem romput tòpics i ens hem atrevit a contar les rondalles a qualsevol espai —damunt una estora a una sala, dins un celler, damunt l'arena a les platges, etc.—, tal com Antoni M. Alcover ens les féu arribar, amb la riquesa d'expressions i paraules amb les quals ell les enriquí, en moltes ocasions sense més recursos que la veu i l'expressivitat del contador o de la contadora.

En paral-lel a les rondalles contades en directe, també hem creat diversos materials didàctics per acompanyar espectacles teatrals que es basaven en les rondalles alcoverianes. Els materials eren ludicodidàctics per ajudar els ensenyants a treure una mica més de profit a la contarella i perquè no quedàs només com un espectacle. Alhora, la Institució Alcover ha publicat directament llibres, CD-ROM i CD de - o sobre- rondalles i ha col-laborat en edicions d'altri. Un dels darrers exemples són les traduccions d'algunes rondalles al rus, txec, romanès i anglès.

\section{Les darreres traduccions de rondalles d'Antoni M. Alcover}

És innegable la importància de les traduccions per fer conèixer l'Aplec de Rondaies Mallorquines fora del territori de parla catalana. Aquest era un tema pendent de la Institució Pública Antoni M. Alcover, que aprofità les circumstàncies favorables per envestir un nou projecte de traducció.

Els precedents d'aquesta tasca s'iniciaren durant els estius dels anys $2007 \mathrm{i}$ 2008, quan la Institució Pública Antoni M. Alcover acollí diverses llicenciades estudiants de català d'universitats de la República Txeca, de Rússia i de Romania.

Es tractà d'una acollida realitzada a proposta del lectorat de català de Praga i consistí en una estada temporal en la qual les persones becades havien de realitzar alguns treballs de suport a la Institució (en un principi, d'inventari i catalogació de materials, per exemple) a canvi de la manutenció i el sojorn, amb l'objectiu de mantenir un contacte amb la vida mallorquina que els permetés practicar i millorar el seu domini del català. L'estada a Manacor que possibilità la Institució Pública Antoni M. Alcover suposà un primer contacte amb la figura d'Alcover i amb les rondalles i l'inici d'una tasca de traducció que durà uns quants anys. Els proposàrem de realitzar la traducció de cinc rondalles, del català al rus, txec i romanès, respectivament.

Després d'una sèrie d'anys de contactes diversos, les joves traductores, que són Anna Urzhumtseva de Moscou, Anca Bărbulescu de Bucarest i Jaroslava Marešová i Jana Vrátníková de Praga, anaren avançant en les respectives carreres com a professionals de la traducció, intèrprets i professores d'universitat, la qual cosa ens permeté reprendre el projecte inicial de traducció de les rondalles proposades. Per decisió conjunta i consensuada, a partir de diferents tipologies i de les preferències personals, s'elegiren cinc rondalles de l'Aplec: «L'amor de les tres taronges», «En Pere de la bona roba», «Els consells del rei Salomó», «En Joanet de la gerra» i «La filla del Sol i de la Lluna». 
El procés de treball no fou fàcil, ja que les rondalles d'Alcover són farcides d'expressions lingüístiques populars i genuïnes de difícil traducció, la qual cosa els suposà un handicap afegit. Per això s'hagueren de cercar canals de comunicació i consulta permanents amb filòlegs i investigadors especialistes en les rondalles d'Alcover. En tot aquest procés, els resultà d'especial utilitat el Diccionari catalàvalencià-balear, del mateix Alcover, ${ }^{8}$ i el Diccionari d'expressions lingüístiques recollides de les Rondaies Mallorquines d'En Jordi des Racó, d'Antoni Llull Martí. ${ }^{9}$ L'objectiu principal de les publicacions era donar a conèixer l'Aplec d'Alcover a altres països i, alhora, la llengua i la cultura catalanes, per la qual cosa s'optà per editar una versió bilingüe dels textos, en català' ${ }^{10}$ i en les llengües respectives: rus, romanès i txec.

Després d'uns anys de feina, els dies 5 i 6 d'abril de 20 II varen tenir lloc els actes de presentació dels llibres respectivament a Palma, a l'Institut Ramon Llull, i, a Manacor, a la Institució Pública Antoni M. Alcover. Aparegueren amb el títol genèric de Cinc rondalles mallorquines d'Antoni M. Alcover i amb el subtítol catalàrus, català-romanès i català-txec, respectivament, i foren publicats en tres volums per la Institució Pública Antoni M. Alcover dins la col-lecció Escorcolls, amb els números 5 , 6 i 7 .

Per tal de completar i fer més atractives les traduccions, encarregàrem la tasca d'il-lustració de les cinc rondalles a cinc artistes joves de reconegut prestigi i d'estils completament diversos: Francesc Barceló, Sebastià Riera, Pere Pasqual, Joan Brunet i Antoni Galmés, que il-lustraren una rondalla perhom.

Tot aprofitant els nombrosos dies d'estada de les traductores a Mallorca amb motiu de la presentació dels llibres, la Institució Alcover organitzà múltiples activitats promocionals i trobades que donaren a conèixer la nova edició de les rondalles i, alhora, l'interès per la llengua catalana que tenen altres països, en aquest cas Rússia, Romania i Txèquia. Les quatre convidades aprengueren català als respectius lectorats de català i, gràcies al bon domini de la llengua i a la seva formació personal com a filòlogues i traductores, envestiren la tasca de traduir les rondalles. Durant els dies d'estada a Mallorca es reuniren amb col-lectius molt diversos com el Col-lectiu de Dones de Llevant, la Federació de Balls de les Illes Balears, amb grups de membres de col·lectius multiculturals, etc., i feren una ruta per diferents centres educatius tant de primària com de secundària. En conjunt, es tractà d'uns dies molt ben aprofitats que cridaren molt l'atenció dels mitjans de comunicació i per això els feren nombroses entrevistes televisives, radiofòniques i per a publicacions diverses.

\footnotetext{
8. Alcover, Antoni M.; Francesc de Borja Moll (I980): Diccionari Català-Valencià-Balear. Palma: Editorial Moll.

9. Llull Martí, Antoni (2008): Diccionari d'expressions lingüístiques recollides de les Rondaies Mallorquines d'En Jordi des Racó. Palma: Editorial Moll.

Io. Per tal de facilitar la lectura i d'homogeneïtzar les formes i, vist que l'objectiu principal de l'edició era fer arribar les rondalles d'Antoni M. Alcover a un lector internacional, s'optà per fer algunes modificacions mínimes al registre col-loquial usat per l'autor. Essencialment es canvià l'article salat per l'estàndard i les formes col-loquials homo per home, noltros per nosaltres, fii per fill, ahont o ont per on, i similars. En cap cas es renuncià a les formes genuïnes i belles del català de Mallorca ni a cap de les expressions lingüístiques que enriqueixen i caracteritzen els textos rondallístics d'Antoni M. Alcover i els converteixen en únics i extraordinaris.
} 
Però les presentacions a Mallorca només foren l'inici del recorregut d'aquestes traduccions de les rondalles. Durant el mes de setembre de 20II, gràcies a l'acollida del lectorat de català de la Universitat Carolina i del Govern d'Andorra, especialment del professor Andreu Bauçà, presentàrem les tres traduccions a Praga, acompanyades d'una conferència sobre la figura d'Antoni M. Alcover que tingué lloc a l'aula de recursos de català de la Universitat Carolina. A la presentació dels llibres de rondalles traduïdes al rus, txec i romanès hi foren presents, altra vegada, les traductores respectives: Anna Urzhumtseva, que vingué des de Moscou; Anca Bărbulescu, des de Romania, i Jana Vrátníková i Jaroslava Marešová, de Praga. D'aquesta manera, retornava al lectorat de català de Praga el resultat de la iniciativa que havia organitzat feia un sèrie d'anys, ja que tot havia començat quan les joves filòlogues, que eren en aquell moment estudiants de català, gaudiren d'una estada a Mallorca durant uns dies per tal de practicar la llengua. A més a més, els llibres han estat repartits a les principals biblioteques dels països respectius i a diversos lectorats de català d'arreu del món.

L'èxit d'aquest projecte ens animà a continuar en aquesta línia i, l'any 20I2, amb el mateix format iniciat l'any anterior, publicàrem la traducció de les mateixes rondalles a l'anglès. En aquesta ocasió, la traductora fou Mònica Marcos Llinàs, llicenciada en filologia anglesa i que ha treballat en temes de traducció; mallorquina però que, des de fa anys, exerceix com a professora de català a la Universitat de Missouri. Actualment hi ha previstes diverses presentacions a Missouri i la participació en un simposi sobre rondalles que s'hi ha de celebrar. Aquesta traducció a l'anglès de les rondalles ha suposat travessar la mar i arribar a Amèrica i, alhora, obrir noves portes al recorregut de l'Aplec alcoverià.

\section{Conclusions}

El camí del qual hem parlat s'inicià en el moment que Antoni M. Alcover se sentí meravellat i emocionat quan descobrí el tresor de les rondalles, cançons i centenars de paraules i expressions. A partir d'aquest moment es posà a recollir una enorme quantitat de rondalles signades amb el pseudònim d'En Jordi des Racó, que s'han anat editant des dels primers moments fins avui. L'aparició de l'Aplec de Rondalles Mallorquines fou elogiada per literats i filòlegs com el francès Frederic Mistral o l'italià G. Pitré, per exemple.

Mallorca és una terra rica en tradicions populars i en rondalles; per això, Antoni M. Alcover recollí, de poble en poble, més de quatre-centes peces —rondalles, llegendes- que s'han anat editant, amb gran èxit i amb diversos formats, des de I886 fins avui de manera ininterrompuda. Per aquesta obra de recol·lecció i publicació de les rondalles, figura entre els primers folkloristes europeus al costat d'Andersen o dels germans Grimm.

A través de les rondalles podem observar el món a partir d'un patró propi de Mallorca i, a la vegada, com un patró universal de convivència, de respecte i d'enteniment. Les rondalles són una porta oberta: són atractives i agraden a tots els públics, tant als petits com als grans, no tenen contraindicacions ni límits d'edat, ans al contrari, entretenen i ensenyen. Les conservam gràcies a l'esforç i la dedicació d'Antoni M. Alcover i a l'estimació que sentia per la seva terra i el seu entorn. Si no fos per ell, aquest tresor que ens ha arribat per via oral de generació en generació s'hauria perdut i avui seria irrecuperable. 
Les nostres rondalles sempre han interessat tant la gent de Mallorca com la de fora, per això les rondalles s'han traduït al llarg del temps. L'edició d'aquestes rondalles en versió catalana i russa, romanesa, txeca i, posteriorment, anglesa es va poder fer gràcies a la iniciativa de la Institució Pública Antoni M. Alcover a partir del detonant de la important tasca del Govern d'Andorra, a través del lectorat de Praga i de la figura d'Andreu Bauçà, d'impulsar la visita d'un grup de llicenciades en filologia, primer estudiants i més endavant professores i traductores de català, a Mallorca, que els permeté entrar en contacte amb la cultura popular mallorquina i amb les rondalles. Així, ara podem gaudir d'una major projecció internacional de les rondalles que han arribat a terres llunyanes gràcies a la bona feina de les filòlogues traductores. El nostre repte és saber-les mantenir vives i adaptar-les al món d'avui perquè puguin seguir un camí de perdurabilitat. 